\title{
Blast Mines: Physics, Injury Mechanisms And Vehicle Protection.
}

\author{
A Ramasamy ${ }^{1-3}$, AM Hill'1, AE Hepper ${ }^{2}$, AMJ Bull' ${ }^{1}$ JC Clasper ${ }^{3}$ \\ ${ }^{1}$ Department of Bioengineering, Royal School of Mines, Imperial College, London, SW7 2AZ; ${ }^{2}$ Injury Modelling \\ Group, DSTL, Porton Down, Wilts; ${ }^{3}$ Academic Department of Military Surgery and Trauma, RCDM, Birmingham.
}

\begin{abstract}
Since World War II, more vehicles have been lost to land mines than all other threats combined. Anti-vehicular (AV) mines are capable of disabling a heavy vehicle, or completely destroying a lighter vehicle. The most common form of AV mine is the blast mine, which uses a large amount of explosive to directly damage the target. In a conventional military setting, landmines are used as a defensive force-multiplier and to restrict the movements of the opposing force. They are relatively cheap to purchase and easy to acquire, hence landmines are also potent weapons in the insurgents' armamentarium. The stand-off nature of its design has allowed insurgents to cause significant injuries to security forces in current conflicts with little personal risk. As a result, AV mines and improvised explosive devices (IEDs) have become the most common cause of death and injury to Coalition and local security forces operating in Iraq and Afghanistan.

Detonation of an AV mine causes an explosive, exothermic reaction which results in the formation of a shockwave followed by a rapid expansion of gases. The shockwave is mainly reflected by the soil/air interface and fractures the soil cap over the mine. The detonation products then vent through the voids in the soil, resulting in a hollow inverse cone which consists of the detonation gases surrounded by the soil ejecta. It is the combination of the detonation products and soil ejecta that interact with the target vehicle and cause injury to the vehicle occupants.

A number of different strategies are required to mitigate the blast effects of an explosion. Primary blast effects can be reduced by increasing the standoff distance between the seat of the explosion and the crew compartment. Enhancement of armour on the base of the vehicle, as well as improvements in personal protection can prevent penetration of fragments. Mitigating tertiary effects can be achieved by altering the vehicle geometry and structure, increasing vehicle mass, as well as developing new strategies to reduce the transfer of the impulse through the vehicle to the occupants. Protection from thermal injury can be provided by incorporating fire resistant materials into the vehicle and in personal clothing. The challenge for the vehicle designer is the incorporation of these protective measures within an operationally effective platform.
\end{abstract}

\section{Introduction}

Anti-vehicle (AV) mines and Improvised Explosive Devices (IEDs) have become a feature of modern warfare [1]. Since World War II, they have become the leading cause of vehicle loss [2]. In a conventional military conflict, landmines have been used as a potent defensive force multiplier (i.e. they enable protection from a larger attacking force), as well as denying the enemy freedom of movement. As they are relatively inexpensive, available and require little technical expertise in deployment, they have been deployed en masse.

For the insurgent, the deployment of landmines against vehicle targets has numerous advantages; not only does this method of warfare debilitate opposing forces, inhibiting their ability to react rapidly and flexibly, but it also challenges the morale of troops [3]. Finally, it allows insurgents to inflict casualties from a distance, with minimal risk of injury to themselves. Recent experience has shown they have the potential to cause multiply injured casualties in a single incident [4-6]. In the current operational theatres of Iraq and Afghanistan, AV mines and IEDs pose the greatest threat to

Corresponding Author: Major Arul Ramasamy, Dept of Bioengineering, Rm 4.28, Royal School of Mines, Imperial College London, SW7 2AZ

Email: a.ramasamy09@imperial.ac.uk
Coalition and local security forces, responsible for $45.6 \%$ (2233/4895) of all combat deaths [7]. A recent review of attacks in Afghanistan has shown an $81 \%$ increase in IED attacks in the past 12 months [8]. It is highly probable that UK troops will face similar threats for the foreseeable future [9], and hence, in this review article, we describe the physics of the vehicle mine blast, the likely mechanisms of injury to vehicle occupants and the development of countermeasures to mitigate this threat in order to inform the clinical management of explosion victims.

\section{The physics of AV Mine Explosion}

When a vehicle triggers a mine, it causes the explosive to detonate. Detonation is a process whereby a shock-wave propagates through a chemical compound and initiates a rapid, exothermic and explosive chemical reaction in its wake (Figure 1a). The chemical reaction releases the potential energy of the explosive via a phase transformation process. The detonation wave leaves a mass of superheated, high-pressure gas, called the detonation products, in its wake. Local pressures are typically of the order of $1.4-3$ million psi whilst temperatures are of the order of $2000^{\circ} \mathrm{C}$ to $6000^{\circ} \mathrm{C}$ [10]. Once the detonation wave has completely consumed the explosive, the detonation products are not in thermal and mechanical equilibrium with their surroundings. Several physical processes then take place that will determine the amount of energy transmitted to a target. 
For a landmine these processes can be characterised by three distinct phases: explosive interaction with the soil, gas expansion to the surface and soil ejecta interaction with the vehicle.

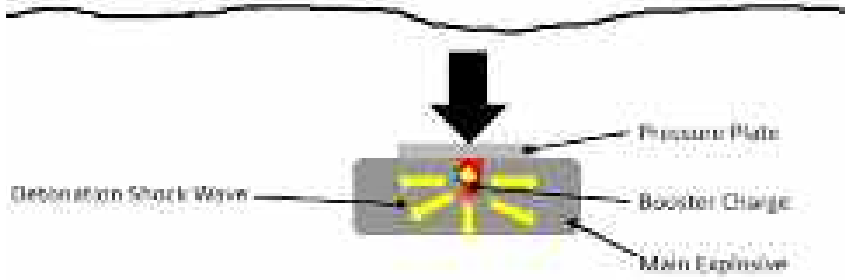

Figure 1a. Activation of the pressure fuse causes the initiation of the booster charge within the landmine. This forms a shockwave that propagates through the explosive to cause a rapid, exothermic chemical reaction.

\section{Explosive Interaction with Soil}

This phase spans the time period from the point at which the explosive has been totally consumed by the detonation wave, to when the resulting detonation products vent through the soil surface. Firstly, heat is transferred to the soil adjacent to the bubble of detonation gases. Secondly, there is transmission of the detonation wave from the detonation products to their immediate surroundings.

The transmitted shockwave compresses the soil material in its wake. When this compression wave reaches the soil-air interface, it is largely reflected downward, back towards the explosion centre [11] (Figure 1b). As the reflected wave propagates downwards, the soil cap is fractured above the detonation products. This, in turn, creates failure planes through which the gas preferentially expands (Figure 1c). In addition, a small fraction of the incident shockwave is transmitted into the air and a thin layer of soil is ejected upwards [12]. This shockwave will therefore produce only a relatively minor load on the vehicle body unless it is in close proximity to the soil/air interface [13].

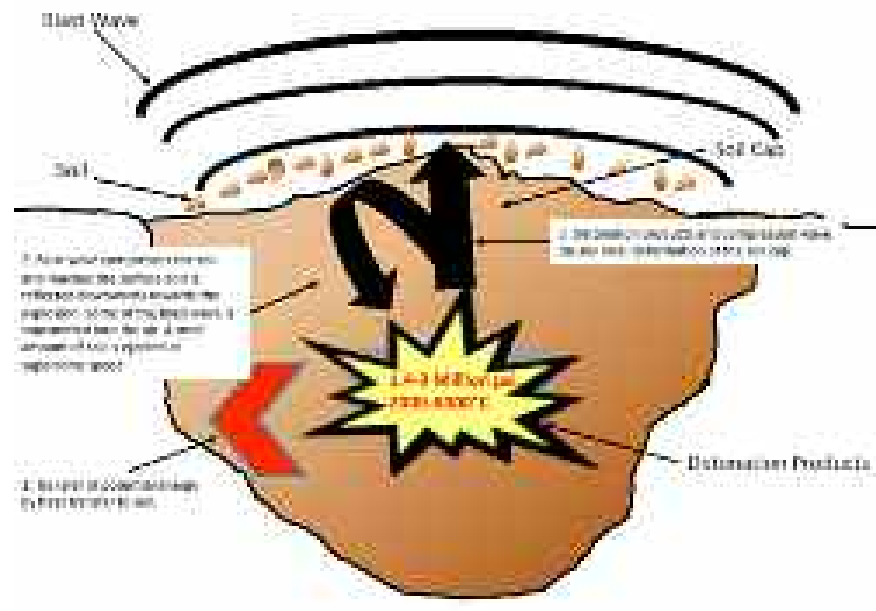

Figure 1b. When the blast wave reaches the soillair interface, only a small fraction is transmitted to the air. The rest is reflected downwards towards the seat of the explosion.

Next, some of the high-pressure gas is propelled (jets) through the voids (failure planes) within the soil; with reference to the Venturi effect, the gas pressure reduces as it flows through these voids within the soil, but its velocity increases to satisfy the equation of continuity (a 'funneling' effect) [14]. Hence, gas gains kinetic energy to a point at which it reaches a state of 'chocked flow' (equivalent to the local speed of sound) where the mass flow rate increases no more, and consequentially, the driving pressure does not reduce either. This sustained high pressure collapses the soil matrix in its immediate vicinity. In the extreme, if the explosion

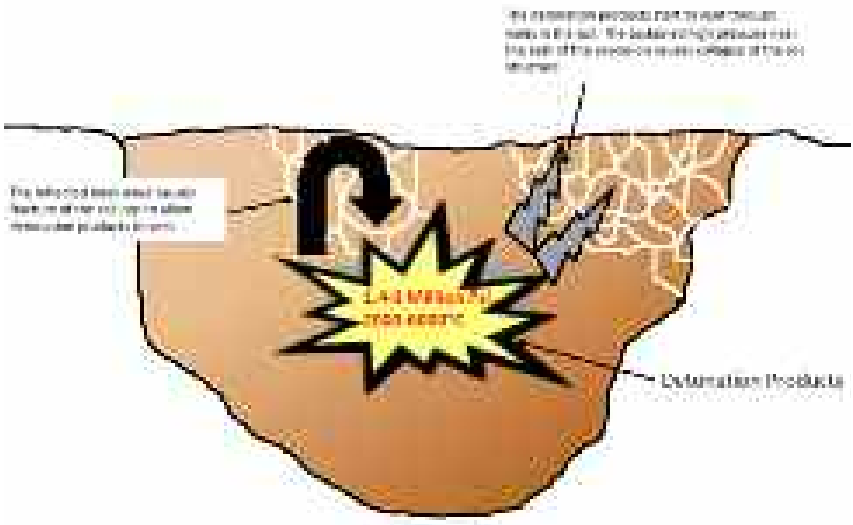

Figure 1c. The blast wave produced is reflected by the air/soil interface and results in a tension wave which ruptures the soil cap.

takes place deep underground, the soil collapse process absorbs all the energy from the detonation. Dependent upon the mine position, the high-velocity gas acts to eject the soil cap. This expands the path of least resistance through which the gas vents. The soil particles are ejected at supersonic speed, between $800-$ $2000 \mathrm{mph}$, depending on soil characteristics and explosive mass [11] (Figure 1d).

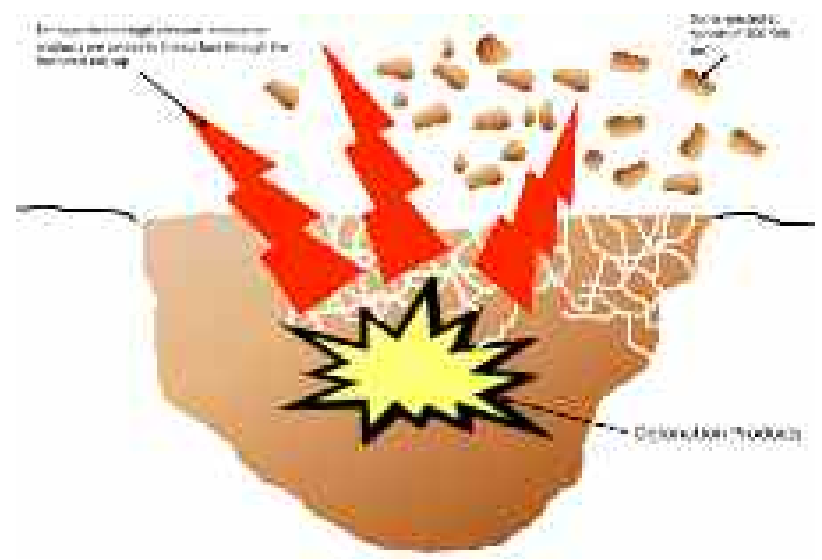

Figure 1d. The detonation products are vented through the voids in the soil resulting in the ejection of soil.

\section{Gas Expansion}

Detonation of the explosive results in the formation of large quantities of gas, determined by the amount of a specific explosive. As the detonation products expand, they eject the soil plug at supersonic speed. The high pressure of the gases will cause localised deformation of the floor of the vehicle if the flow is hindered by the vehicle. The direction and amount of the gas expansion is heavily dependent on the soil properties. Increased soil density and higher moisture content results in a more incompressible soil which directs more of the detonation products in a more vertical direction [15].

\section{Soil Ejecta}

The soil ejecta phase occurs towards the end of the gas expansion phase. It is set in motion by the force of the original explosion and manifests itself via two primary modes of action. First, a radial compression wave propagates outwards in the soil. It sets particles in motion and causes the soil surface to buckle. This poses little threat to the target except for target parts that are in direct contact with the soil. The second mode of action takes place at the boundary of the crater being formed. There, the flow shears the soil and soil particles are carried away in a net upward direction towards 
the vehicle. These accelerate along curved paths due to the combination of upward thrust followed by the rapid radial acceleration of the hot gas. The net result is typically that a hollow cone of soil ejecta, with a projection angle of between $45^{\circ}$ and $120^{\circ}$, flows around a core of expanding hot gas (Figure 1e). It can act on a target for at least 20 to $100 \mathrm{~ms}$ longer than the gas expansion phase. The flow of ejecta is more vertical when the mine is buried deeper, or if the soil is more dense, or has higher moisture content [15]. The physical momentum transfer from the soil ejecta to the vehicle will cause vertical displacement of the vehicle, resulting in significant injury to the occupants.

In summary, the chemical reactions within the activated mine cause an explosive, exothermic reaction which results in the formation of a shockwave followed by a rapid expansion of gases. The shockwave is mainly reflected by the soil/air interface and fractures the soil cap over the mine. The detonation products then vent through the voids in the soil, resulting in a hollow inverse cone which consists of the detonation gases surrounded by the soil ejecta. It is the combination of the detonation products and soil ejecta that interact with the target vehicle and consequently result in injury to the vehicle occupants.

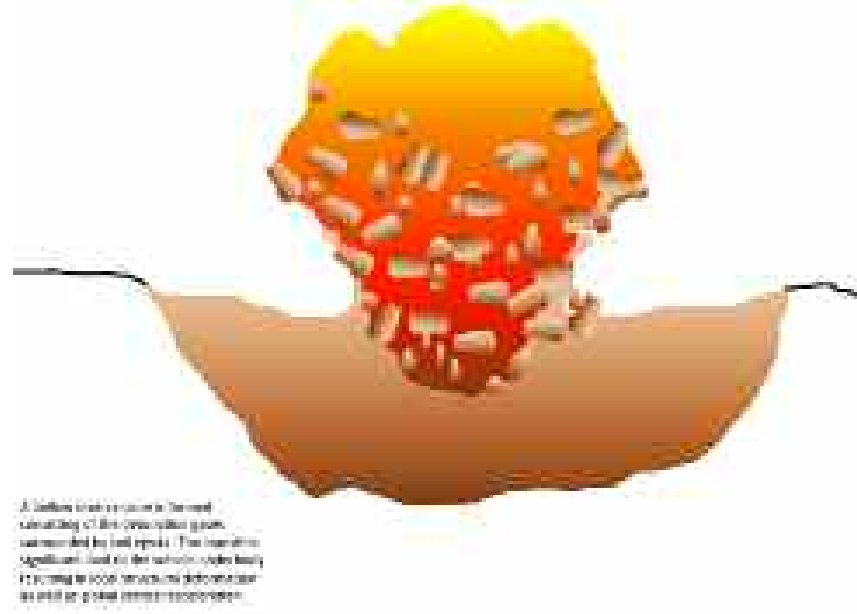

Figure 1e. The hollow inverse cone consisting of the soil ejecta and the detonation gases.

\section{Interaction of explosive products with vehicles}

As described previously, the two dominant load transfer mechanisms to the target vehicle is the expansion of the detonation products and the physical momentum transfer from soil ejecta. For a typical anti-vehicular mine which is $5-8 \mathrm{~kg}$ of high explosive, the gas expansion occurs during the first $5-10 \mathrm{~ms}$ after detonation. The soil ejecta phase takes place shortly thereafter and lasts between 50$100 \mathrm{~ms}$.

The gas phase provides the first phase of this impulse. During this phase, any portion of the vehicle located in the expansion zone of the detonation products is exposed to a high pressure, transient, supersonic flow field. The transfer of momentum from the detonation products to the vehicle is governed by its gas dynamics characteristics. This, in turn, is a direct function of local and global target geometry. If a body is sufficiently slender, the flow adapts to the boundary through a system of oblique shock waves that effectively "bend" the path of the flow that follows a path of least resistance (Figure 2). If the angle imposed by the vehicle floor is greater than the limiting turn angle, the flow experiences a rapid slow down and pressure concentration; flat vehicle floors trap the detonation product and allow time for considerable energy transfer to occur. This often causes rupture of the floor pan and endangers the occupants who are then exposed to lethal secondary fragments and hot gases. Even in cases where floor rupture does not occur, rapid deflection of floor plates in localised regions present a great danger to occupants.

The pressure concentration acts on the whole vehicle and results in vertical acceleration of the vehicle. The magnitude of the vertical displacement is dependent upon the total mass and, for asymmetric loading, on the moments of inertia around the centre of mass, which is a function of the load distribution of the combined vehicle and occupants. After reaching the peak of its force dependent displacement, the vehicle will accelerate to the ground under the effects of gravity, potentially resulting in significant injury, especially if the occupants are not appropriately restrained.
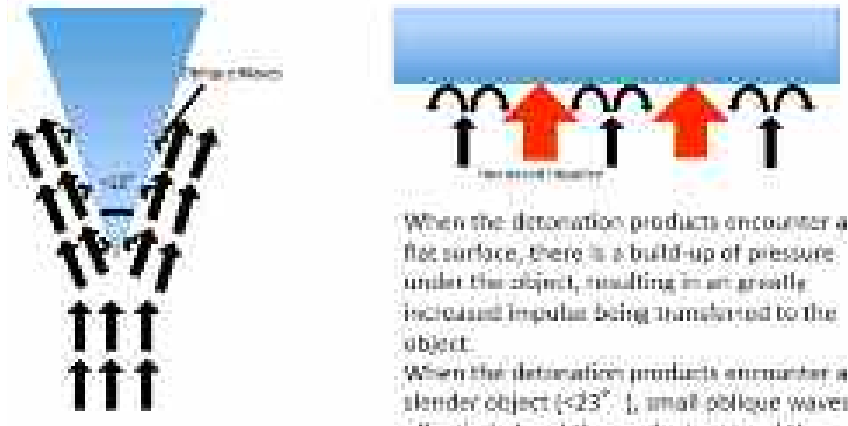

When the defonation prodicts encoincer a Hee sarfoce, there a a buld tup of piesure

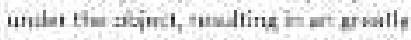
incicase impulat beire thangtived to the object

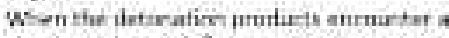

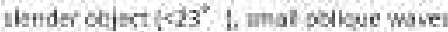
eftectieic berd the pmich alound the

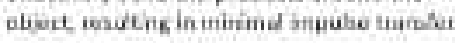

Figure 2. The flow of detonation products is related to the geometry of the vehicle. A slender profile will allow the products to flow and thereby reduce the impulse transferred to the target. Conversely, a flat surface will result in significant pressure concentration beneath, resulting in significant load transfer to the vehicle and its occupants.

\section{Human Effects from AV mine explosions}

AV mine explosions cause injury in a variety of mechanisms. Classically, any injury from a generic explosion can be categorised into four types; primary, secondary, tertiary and quaternary blast injury.

Primary blast injuries are caused by the sudden increase in air pressure after an explosion. Air containing organs, such as the lungs and gastro-intestinal tract are susceptible to the effects of the blast wave. Pulmonary effects are seen at 70 psi. Exposure to pressures above 80 psi is associated in death for more than $50 \%$ of cases [16]. In a vehicle mine blast, the standoff distance between the mine and the crew compartment, the interaction of the blast wave with the soil and air interface and the interaction between the blast wave and the vehicle structure will mitigate the primary blast effects on the occupants. Holcomb et al showed that the peak overpressure outside an armoured vehicle was 28 times greater than inside the vehicle following the detonation of a $17 \mathrm{~kg}$ bare charge located 3 metres away [17]. Therefore, primary blast injury is unlikely unless the vehicle body is in close proximity to the ground, or if a large explosive device is detonated.

Secondary blast injuries occur when bomb fragments or nearby debris are energised by the explosion and cause injury by penetrating trauma. These fragments have varying levels of lethality. Small fragments, as seen from anti-personnel mines are a less severe threat to the crews and can be defended against through light armour. Large heavy fragments (eg projectiles formed in shaped charge explosives) possess huge amounts of kinetic energy and pose a severe threat to the vehicle occupants $[6,18]$. The risk of crew compartment penetration can be reduced by the application of armoured plates to the underside of the vehicle.

Tertiary blast injuries are caused when the casualty is thrown by the explosion and collides with nearby objects, or if there is deformation of the crew compartment. They can be considered to have both local and global effects. Local deformation of the floor 
plate will apply significant axial load to the passenger resulting in lower limb, pelvic and spinal fractures.

Gross vehicle acceleration and subsequent collisions are also a significant source of injury, especially if the occupant is not suitably restrained. The mass of the vehicle has a significant effect on the global acceleration of the vehicle, and hence on load transfer from the blast to the vehicle occupants. Making use of the basic relationship between force, mass and acceleration, it is seen that the global acceleration, $\alpha$, is inversely proportional to mass, $(\alpha=F / m)$. For a given mine threat, and the same vehicle geometry, lighter vehicles (small mass $\mathrm{m}$ ) suffer a greater resultant acceleration $(\alpha)$. The lighter vehicles will also reach higher velocity and greater displacement compared to a heavier vehicle. Consequently, the occupants of lighter vehicles are more at risk of suffering a serious vertical acceleration injury such as lumbar spine injury and axial loading to the lower limbs. Unrestrained occupants may also incur significant head injuries from striking the roof of the vehicle or from being ejected out of the vehicle. Vehicle occupants also have the risk of injury from poorly stowed or inadequately restrained equipment.

Tertiary blast effects are the most significant injury mechanism in a vehicle mine blast and measures to attenuate this effect remain key to reducing mortality and morbidity in vehicle occupants. This is especially true as improvements in armour technologies have afforded better protection against secondary blast fragments.

Quartenary blast injuries are related to the thermal effects of the blast, toxic effects, and any post-incident risks [such as drowning or freezing].

The clinical effects of these injuries and potential mitigation strategies are summarised below (Table 1 and Figure 3).

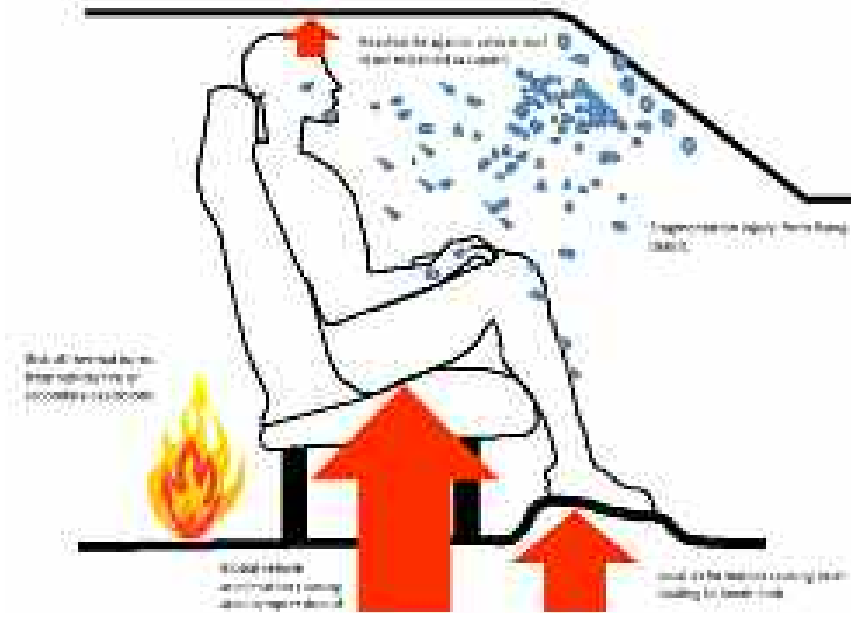

Figure 3. The effects of AV mine blast on human occupants.

\section{Development of AV Mine Protection}

A number of different strategies are required to mitigate the four blast effects from explosion. Primary blast effects can be reduced by increasing the standoff distance between the seat of the explosion and the crew compartment. Enhancement of armour on the base of the vehicle, as well as improvements in personal protection can

\begin{tabular}{|c|c|c|c|c|c|}
\hline BLAST INJURY & $\begin{array}{l}\text { MECHANISM } \\
\text { OF INJURY }\end{array}$ & $\begin{array}{l}\text { CLINICAL } \\
\text { EFFECTS }\end{array}$ & $\begin{array}{c}\text { MITIGATION } \\
\text { REQUIREMENT }\end{array}$ & $\begin{array}{l}\text { VEHICLE } \\
\text { MITIGATION }\end{array}$ & $\begin{array}{l}\text { INJURY } \\
\text { SEVERITY }\end{array}$ \\
\hline PRIMARY & $\begin{array}{c}\text { Blast } \\
\text { shockwave }\end{array}$ & $\begin{array}{l}\text { Primary Blast } \\
\text { Lung, } \\
\text { Gastrointestinal } \\
\text { injury, soft tissue } \\
\text { deformation }\end{array}$ & $\begin{array}{c}\text { Reduce } \\
\text { blast transfer }\end{array}$ & $\begin{array}{c}\text { Increased standoff } \\
\text { and improved gas } \\
\text { dynamic } \\
\text { characteristics } \\
\text { mitigating brisance } \\
\text { and the inclusion of } \\
\text { blast mitigating } \\
\text { materials }\end{array}$ & $\begin{array}{c}* \\
\text { (unless vehicle body } \\
\text { penetration, in } \\
\text { which case } \\
* * * \text { ) }\end{array}$ \\
\hline SECONDARY & $\begin{array}{l}\text { Fragments from } \\
\text { mine products } \\
\text { Energised soil ejecta } \\
\text { and vehicle } \\
\text { fragments }\end{array}$ & $\begin{array}{l}\text { Penetrating wounds } \\
\text { particularly to the } \\
\text { lower extremity and } \\
\text { facial injuries from } \\
\text { glass fragments. }\end{array}$ & $\begin{array}{c}\text { Reduce fragments, } \\
\text { or protect against } \\
\text { fragments }\end{array}$ & $\begin{array}{l}\text { Improved armour } \\
\text { protection of } \\
\text { vehicle floor and } \\
\text { improved personal } \\
\text { protection. }\end{array}$ & ** \\
\hline TERTIARY & $\begin{array}{l}\text { Global - vehicle } \\
\text { acceleration. } \\
\text { Local - Floor pan } \\
\text { defomation. }\end{array}$ & $\begin{array}{c}\text { Significant axial } \\
\text { loading leading to } \\
\text { lower limb (especially } \\
\text { calcaneal), pelvic and } \\
\text { spinal injuries. } \\
\text { Head injuries from } \\
\text { collision with vehicle } \\
\text { roof. }\end{array}$ & $\begin{array}{l}\text { Reduce vehicle } \\
\text { acceleration, reduce } \\
\text { capture of pressure } \\
\text { wave by vehicle, } \\
\text { increase resistance } \\
\text { to floorplate } \\
\text { geometrical changes }\end{array}$ & $\begin{array}{l}\text { Increased standoff. } \\
\text { V-shaped hull } \\
\text { design. } \\
\text { Occupant restraints } \\
\text { to prevent collision } \\
\text { injuries. }\end{array}$ & $* * *$ \\
\hline QUARTENARY & $\begin{array}{l}\text { Thermal } \\
\text { injuries }\end{array}$ & Burns & $\begin{array}{c}\text { Protect } \\
\text { agains burns }\end{array}$ & $\begin{array}{l}\text { Fire resistant } \\
\text { materials in } \\
\text { vehicles } \\
\text { and fire retardant } \\
\text { clothing. }\end{array}$ & $* * *$ \\
\hline
\end{tabular}

Table 1. Summary of human effects in AV Blast. 
prevent penetration of small fragments, although protection from large fragments may be challenging. Mitigating tertiary effects can be achieved by altering the vehicle geometry, increasing vehicle mass, as well as developing new strategies to reduce the transfer of the impulse through the vehicle to the occupants. The correct design and stowage of equipment and personal restraint also mitigate tertiary injuries. Protection from thermal injury can be afforded by the incorporation of fire resistant materials into the vehicle and in personal clothing. The challenge for the vehicle designer is the integration of these protective measures within an operationally effective platform (Table 1).

Historically, the development of mine resistant vehicles can be categorised into four groups based on the sophistication of the design and the ability to retrofit current vehicle platforms [19] (Table 2).

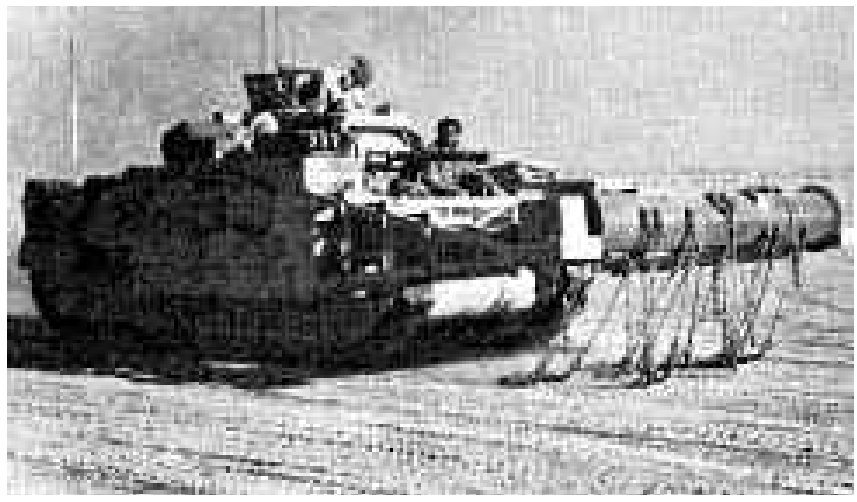

Figure 4. The Matilda-Scorpion Flail Tank. The Flails were designed to detonate the mines in order to create a clear passage through a mine field.

\begin{tabular}{|c|c|c|c|}
\hline GENERATION & DETAIL & $\begin{array}{l}\text { MITIGATION } \\
\text { REQUIREMENT }\end{array}$ & $\begin{array}{l}\text { MITIGATION } \\
\text { DESIGN }\end{array}$ \\
\hline $\begin{array}{c}\text { 1st } \\
\text { GENERATION }\end{array}$ & $\begin{array}{l}\text { Improvised protection kits } \\
\text { fabricated by soldiers in the } \\
\text { field. }\end{array}$ & $\begin{array}{c}\text { Prevent penetration of secondary } \\
\text { fragments. } \\
\text { Reduce vehicle acceleration. } \\
\text { Reduce pressure of detonation } \\
\text { products. }\end{array}$ & $\begin{array}{l}\text { Addition of sandbags and Conveyor } \\
\text { belting to floor of vehicle. } \\
\text { Increased mass of the vehicle. } \\
\text { Occupant restraints. } \\
\text { Water-filled tyres. }\end{array}$ \\
\hline 2nd GENERATION & $\begin{array}{l}\text { Retrofit kits that are } \\
\text { developed and provided to } \\
\text { the units for installation in } \\
\text { the field. }\end{array}$ & $\begin{array}{c}\text { Allow venting of detonation } \\
\text { products. } \\
\text { Prevent penetration of } \\
\text { secondary fragments. }\end{array}$ & $\begin{array}{l}\text { Installation of blast deflectors } \\
\text { around wheel arches. }\end{array}$ \\
\hline 3rd GENERATION & $\begin{array}{l}\text { Vehicles equipped with mine } \\
\text { resistant hull mounted above } \\
\text { the vehicle frame. }\end{array}$ & $\begin{array}{l}\text { Allow venting of detonation } \\
\text { products. } \\
\text { Reduce impulse transfer from } \\
\text { detonation products and soil ejecta. }\end{array}$ & $\begin{array}{l}\text { V-shaped hull. } \\
\text { Increased ground clearance. }\end{array}$ \\
\hline 4th GENERATION & $\begin{array}{l}\text { Specially built vehicles } \\
\text { equipped with a monocoque } \\
\text { mine resistant hull.. }\end{array}$ & $\begin{array}{l}\text { Remove crew compartment } \\
\text { from zone of injury. }\end{array}$ & Increased spacing of wheels. \\
\hline
\end{tabular}

Table 2. Historical development of vehicle mine protection

\section{$1^{\text {st }}$ Generation Developments - Field Improvisation}

The first attempts at mine-protection occurred during the North Africa campaign in the Second World War (WW2). The North African desert, open and desolate, was ideal for tank battles. To counter the initial dominance of the Germans Panzers, the Allied forces laid vast minefields with a mine density of $2 / \mathrm{m}^{2}$. When the Germans retreated, the Allies were left with the difficulty of salvaging equipment and mapping out unmarked minefields that covered large areas of the desert. They employed Pilot vehicles which were used to define the edge of minefields by detonating the mines under its rollers. The floors of these trucks were heavily sandbagged in order to prevent secondary fragments and to reduce vehicle acceleration by increasing the weight of the vehicle. It was assumed that the vehicle itself would be severely damaged by the blast, but the driver would hopefully survive [20]. Following WW2, very little development in producing mine resistant vehicles was achieved. With the emergence of the Cold War, military forces instead focused their development on mine clearance vehicles such as flail tanks (Figure 4) and armoured bulldozers to clear routes through mine fields.
It was during the Rhodesian Bush War (1972-1980) that further iterations in mine protection vehicles were produced. The Rhodesian security forces fought a counter-insurgency operation against Zimbabwean nationalists whose principal weapon of attack was the Soviet TM-46 anti-tank mine [21]. The TM-46 is a pressure-fused blast mine that consisted of a $5.3 \mathrm{~kg}$ high-grade explosive charge. As a result of international sanctions, the Rhodesian government, unable to purchase armour or armoured vehicles, set up a multidisciplinary countermine committee to explore novel approaches to mine protection [3]. Based on iterative experience, they developed a suite of mine-protection vehicles.

Their initial development included the use of sandbags covered with conveyer belt rubber to prevent small fragments from entering the passenger compartment. Although partially successful in heavy vehicles, they interfered with the driving controls and caused some accidents [3]. They also wore down quickly, the sand interfering with the driver's vision as well as overloading the vehicles. Their most significant basic modification was filling the tyres of Bedford trucks with 100 litres of water and then pumping up the tyres up to 44 psi. Keenan and Wager [22] suggest that the blast waves from the explosion cause the water to become an aerosol and then evaporate upon mixing with the detonation products. This causes the detonation gases to cool down and the gas pressure to decrease 
and thereby reduce the impulse seen by the vehicle. Although successful, this method also had a very significant disadvantage. The partially filled tyre placed considerable strain on the drive train of the vehicle, resulting in broken gear boxes, clutches, differential gears and bearings [3]. There was also anecdote to suggest that the tyres prevented vehicles traversing steep banks and consequently made them vulnerable to ambushes at these sites.

In addition to physical modifications, the Rhodesian forces also instigated strict vehicle discipline in an attempt to reduce tertiary blast injuries in unrestrained occupants. They ensured that all vehicle occupants had to be securely restrained. All equipment had to be stowed away in closed containers, so that they could not become secondary fragments in a blast. They also enforced a strict speed limit in high-risk environments to reduce the effects of the inevitable vehicle collision following a mine blast [3].

The increase in mine incidents in Rhodesia, over 5000 mine incidents were recorded over 6 years (a figure comparable to total Allied WW2 vehicle mine attacks from June 1944-May 1945), meant that the security forces had to develop a new suite of vehicles to counter this threat [21]. The next iteration of vehicle modification involved the retrofitting of existing vehicle platforms to improve mine protection.

\section{$2^{\text {nd }}$ Generation - Retrofit Kits}

AV mines are predominantly victim operated and are detonated when a wheel comes in contact with the pressure fuse. Therefore, the wheel arches would be in the seat of the explosion. To shield the crew cab from the blast, the Rhodesians developed angled steel blast deflectors that were welded to the chassis. The blast deflectors allowed venting of the detonation gases away from the crew compartment as well as provide extra protection from secondary blast fragments.

These design features combined with a strict driving policy had a significant effect on both fatalities and injuries from mine blast. Based on their meticulous mine incident data, they reported a reduction of fatalities from $45 \%$ in unprotected light vehicles to $9 \%$ in protected vehicles [23].

\section{$3^{\text {rd }}$ Generation Developments - V-shaped}

Despite the successful outcome from the initial developments, there was a drive for further developments to improve not only a reduction in fatality but also to reduce the number and severity of injuries incurred. This led to the development of $\mathrm{V}$-shaped crew compartments that sat high on the vehicle chassis. Based on the physics of mine detonation, the pressure concentration under a flat-bottomed platform compared to a V-shaped platform is significantly reduced. The detonation products flow better along a V-hull than is the case for a flat hull; thereby reducing the impulse transferred to the vehicle (Figure 2).

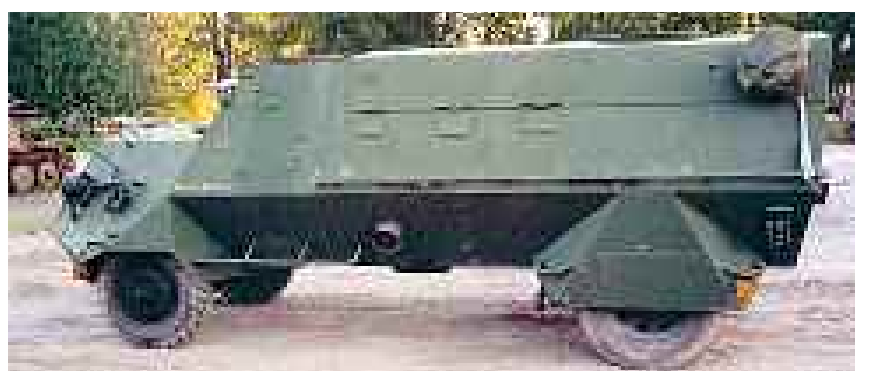

Figure 5. The Swedish SKPF M/42 Armoured Personnel Carrier developed during WW2 was the first vehicle to incorporate the $V$ shaped hull to aid deflection of the detonation products. This feature was later included in both Rhodesian mine vehicles and in modern coalition mine-protected vehicles.
Field experiments have shown that a V-shaped hull will only be propelled a third of the height compared to a flat hull exposed to the same amount of explosive [11]. Although V-shaped hulls were considered to be one of the major breakthroughs achieved during the Rhodesian conflict, their origins can be traced back to World War II. The Swedish SKPF M/42 Armoured Personnel Carrier (Figure 5) was the first vehicle to have a V-shaped hull design and it remained in operation until the 1980s serving in the Congo, Cyprus and the Gaza Strip.

\section{$4^{\text {th }}$ Generation Developments - Monocoque Hulls}

The monocoque vehicle, developed by Ernest Konschel, was designed to eliminate the chassis from the most likely blast area and take the wheels out from under the vehicle body [3]. As the detonating gases expand in a vertical inverse-cone configuration (Figure 1e), the 'cab over wheel' configuration will place the crew compartment within the zone of possible injury. With Konschel's design the crew compartment will be more protected as there is a lateral stand-off from this zone of vertical flow. The front and back wheel assemblies were attached to the passenger capsule by sheer bolts. When a wheel detonated a mine, the blast would cut the bolts and the capsule would drop down on the road. The monocoque hull design allowed the drive train and gearbox of the vehicle to be protected by the hull and the smooth vehicle surface eliminated the risk of the weak areas formed by welds or joints (Figure 6). These vehicles developed at the end of the Bush War, when mine incidents reached a peak of 2376 in 1979, had a remarkable effect in reducing fatalities. From 676 mine incidents, carrying 4874 passengers, the fatality rate was reduced to only $0.8 \%(42 / 4874)$ and the injury rate to $18.4 \%$ (906/4874).

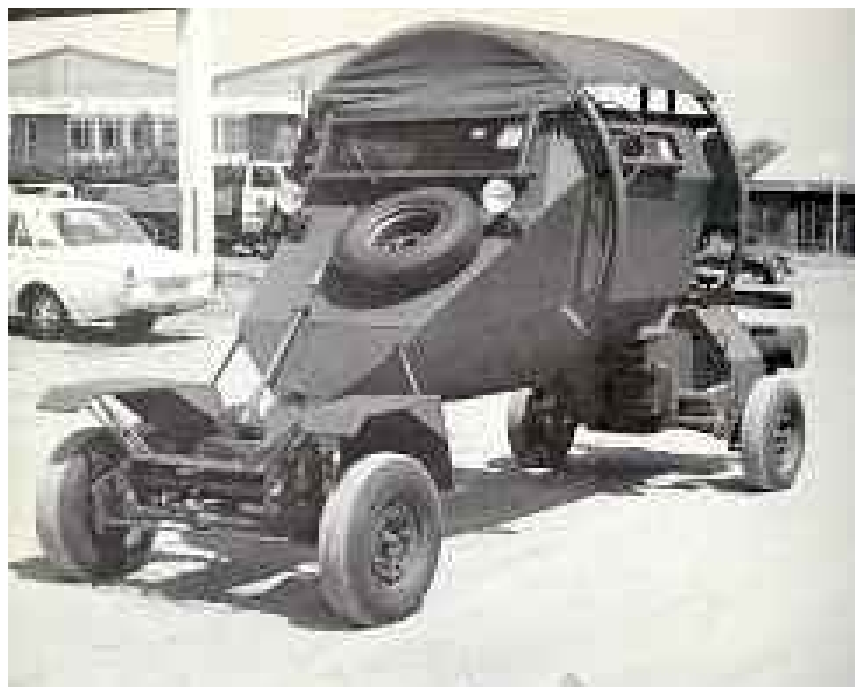

Figure 6. The Leopard. It incorporated the V-shaped hull with the single monocoque hull which provided protection to the drive-train as well as the passenger compartment. The increased axle length brought the wheels outside the passenger compartment and the easily sheared connection meant that the wheel assembly would be blown clear of the vehicle if it detonated a mine. (Source: Ernest Konschel. Available from: http://www.baragwanath.co.za/leopard/)

\section{Current Considerations}

Many of the protective measures described above have been incorporated into modern US and UK military patrol vehicles that are operating in Iraq and Afghanistan [24]. Although the AV mine and IED threat remains very high, Coalition and local Security Forces are faced with numerous other threats that are synonymous with counter-insurgency warfare. Therefore, the design of vehicles 
must be sensitive to the need to protect against these threats (eg ambush, RPGs etc.), as well as maintaining mobility and situational awareness.

The main design feature in mine protection remains to increase the distance between the occupants and the blast centre. However, incorporating this increased standoff will necessitate a larger vehicle platform, which introduces further complications. From a personnel threat perspective, a taller vehicle platform increases its visibility, thereby making the vehicle more vulnerable to ambush. In operational terms, the key to success in counter-insurgency operations is winning and maintaining the consent of the indigenous population [25]. This is can be made more difficult if Coalition troops enter towns and villages, driving imposing armoured vehicles. Similarly in large population centres, the streets are often too narrow for these vehicles to use (Figure 7). Therefore, vehicle designers must be cogniscent of these conflicting needs, as there will always be a requirement for the Armed Forces to develop a suite of vehicles that can cater for both the environment and the current threat state.

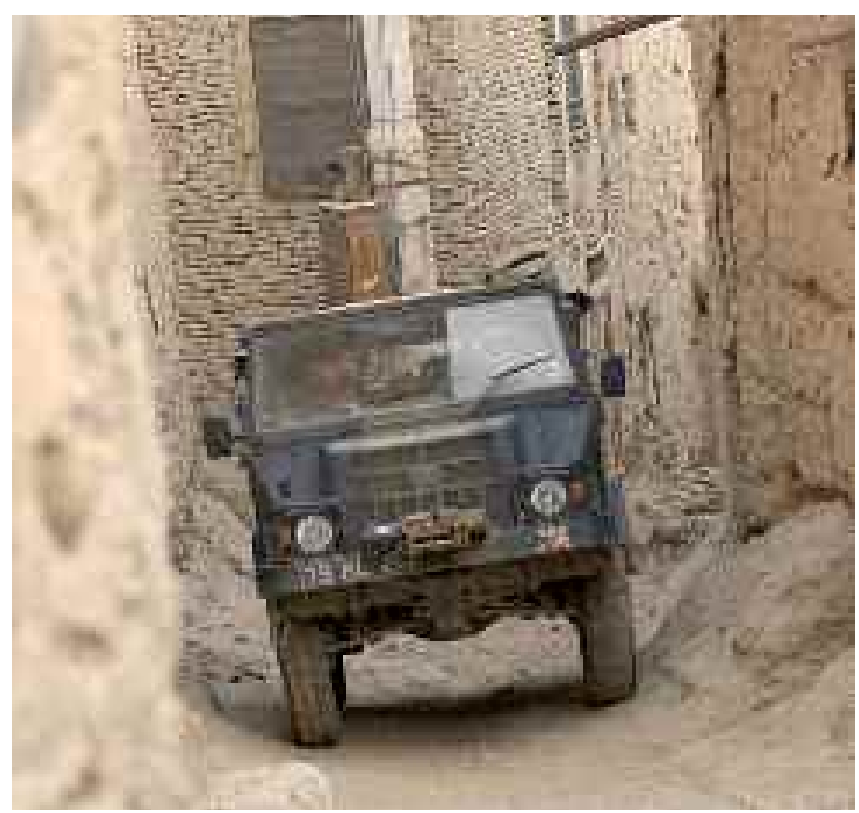

Figure 7. The narrow streets of Afghanistan may prevent the use of large vehicle platforms. (Image: $M O D$ archives)

\section{Conclusions}

The development of mine protection strategies is multifaceted and requires a collaborative approach between engineers, scientists and clinicians to fully understand the interaction of the blast with the vehicle and its relationship to human injury. Physical protection remains only one element in the attempt to reduce injury. Improvements in mine detection, countermeasures and tactics are equally important in preventing injury and enabling security forces to move unhindered within a high mine threat environment.

There is no way that a vehicle can be fully mine-proofed. If the insurgent is able to plant enough explosive, any vehicle can be penetrated. However, by applying mine protection principles and tactics it is possible to increase the insurgents' logistical and operational problems to the point where the tactic of mining vehicles is of limited value, other than in exceptional circumstances.

\section{References}

1. Ramasamy A, Hill AM, Clasper JC. Improvised Explosive Devices: pathophysiology, Injuries and Management. J R Army Med Corps 2009; 154[4]: 265-72.

2. Bird R. Protection of vehicles against landmines. Journal of Battlefield Technology 2001;4[1]:14-7.

3. Stansfield I. A Paper on Mine Protection of Military Vehicles. Salisbury, Rhodesia: Mine warfare committee1982.

4. Owens BD, Kragh JF, Jr., Wenke JC, Macaitis J, Wade CE, Holcomb JB. Combat wounds in operation Iraqi Freedom and operation Enduring Freedom. J Trauma. 2008;64[2]:295-9.

5. Ramasamy A, Harrisson S, Lasrado I, Stewart MP. A review of casualties during the Iraqi insurgency 2006--a British field hospital experience. Injury. 2009; 40[5]:493-7.

6. Ramasamy A, Harrisson SE, Clasper JC, Stewart MP. Injuries from roadside improvised explosive devices. J Trauma. 2008;65 [4]:910-4.

7. icasualties.org. iCasualties: Coalition Casualty Count. accessed 22 Jun 09; Available from: http://icasualties.org/Iraq/IED.aspx.

8. NATO. Unclassified metrics. Kandahar, Afghanistan: Strategic Advisory Group. 9 May 2009.

9. Dannatt R. A perspective on the nature of future conflict. In: Chatham House, editor. London: Chatham House; 2009.

10. Baker W, Cox P, Westine P, Kulesz J, Strehlow R. Loading from Blast Waves. In: Baker W, Cox P, Westine P, Kulesz J, Strehlow R, editors. Explosion Hazards and Evaluation. Amsterdam: Elsevier; 1983.

11. Tremblay J, Bergeron DM, Gonzalez R. KTA 1-29: Protection of Soft-Skinned Vehicle Occupants from Landmine Effects. In: Program TTCP, editor. ValBelair, Canada: Defence Research Establishment Valcartier, Quebec, Canada; 1998.

12. Grujicic M, Pandurangan B, Zhao CL, Cheeseman B. A Computational Investigation of Various Water-induced Explosion Mitigation Mechanisms. Multidiscipline Modeling in Materials and Structures. 2007;3[2]:185-212.

13. Bergeron DM, Tremblay JE, editors. 16th International MABS Symposium; Sept 2000; Oxford, UK

14. Tipler P, Mosca G. Physics for Scientists and Engineers. 6th ed. New York: WH Freeman; 2007.

15. Grujicic M, Pandurangan B, Qiao R et al. Parameterization of the porousmaterial model for sand with different levels of water saturation. Soil Dynamics and Earthquake Engineering. 2008;28:20-35.

16. Mellor SG, Cooper GJ. Analysis of 828 servicemen killed or injured by explosion in Northern Ireland 1970-84: the Hostile Action Casualty System. Br J Surg. 1989;76[10]:1006-10.

17. Champion HR, Holcomb JB, Young LA. Injuries from explosions: physics, biophysics, pathology, and required research focus. J Trauma. 2009 ; 66[5]:1468-77

18. Morrison J, Mahoney P, Hodgetts T. Shaped Charges and Explosively Formed Penetrators: Background for Clinicians. JR Army Med Corps 2007;153[3]:184-7.

19. Schneck W. The Development of Mine Resistant Vehicles. Virginia, USA. Belvoir RD\&E Centre, Directorate CS;1994.

20. Stiff P. Taming the Landmine. 1st ed. Alberton, RSA: Galago publishing; 1986.

21. An analysis of mine incidents encountered in Zimbabwe Rhodesia during 1979. In: G. Branch Engineering Directorate, editor. Salisbury, Rhodesia: Rhodesian Army; 1980.

22. Keenan W, Wager P Eds.. Mitigation of confined explosion effects by placing water in proximity of explosives. 25th DoD Explosives Safety Seminar; 18-20 Aug 1992.; Anaheim, CA.

23. Lester C. Protection of light skinned vehicles against landmines - a review. Melbourne, Victoria.: DSTO1996 Contract No.: DSTO-TR-0310.

24. Mastiff 2. Ministry of Defence; 2009. accessed 24 Jun 2009; Available from: http://www.army.mod.uk/equipment/fighting-vehicles/1487.aspx.

25. Bricknell MC, Gadd RD. Roles for international military medical services in stability operations [reconstruction and development]. J R Army Med Corps. $2007 ; 153[3]: 160-4$. 